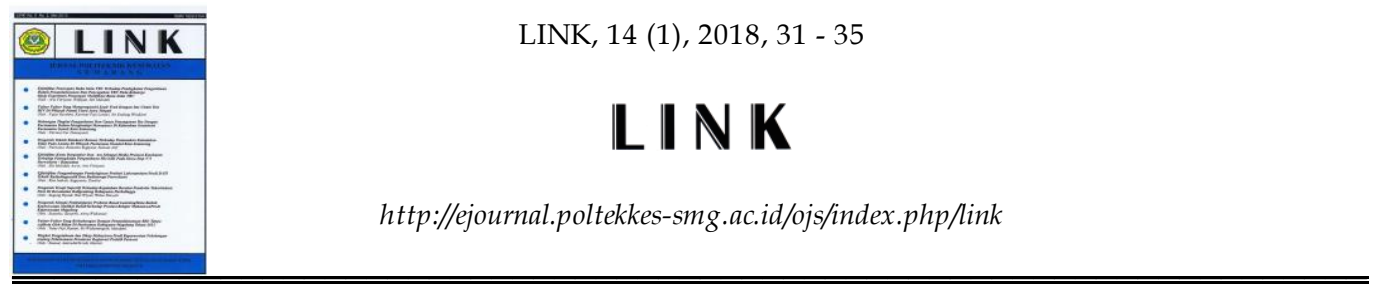

\title{
PENERAPAN MEDIA SOFTWARE INTERAKTIF SEBAGAI MEDIA EDUKASI DALAM PERUBAHAN TINGKAT PENGETAHUAN DAN PERILAKU KESEHATAN GIGI SERTA TINGKAT KEBERSIHAN GIGI
}

\author{
Ani Subekti*) ; Bambang Sutomo ; Bedjo Santoso ; Salikun ; Rizki Amalia ; Ratna \\ Puspita ; Kharismana Umia \\ Jurusan Keperawatan Gigi ; Poltekkes Kemenkes Semarang \\ Jl. Tirto Agung ; Pedalangan ; Banyumanik ; Semarang
}

\begin{abstract}
Abstrak
Struktur gigi pada masa anak-anak usia dini adalah periode gigi susu yang rentan mengalami karies gigi. Karies gigi ialah pembentukan lubang permukaan gigi disebabkan kuman dan terbentuk pada permukaan gigi terbuka yaitu mahkota gigi terkait perilaku pemeliharaan kesehatan gigi yang dipengaruhi faktor individu dan di luar individu. Tujuan pengabdian masyarakat ini adalah terjadi perubahan tingkat pengetahuan dan perilaku tentang kesehatan gigi dan mulut serta tingkat kebersihan gigi dan mulut anak-anak PAUD Mutiara Pedurungan setelah diberikan penyuluhan menggunakan software interaktif sebagai media edukasi. Metode pelaksanaan pengabdian ini dengan memadukan beberapa tahap kegiatan yaitu: Pengambilan data awal dengan melakukan pemeriksaan kebersihan gigi, tingkat pengetahuan anak dan perilaku menyikat gigi kepada sasaran, Tahap intervensi: Penyuluhan Program software, Demonstrasi menyikat gigi, Monitoring selama seminggu dan dua minggu dengan pantauan orangtua di rumah. Pengambilan data akhir dengan melakukan pemeriksaan kebersihan gigi, tingkat pengetahuan anak dan perilaku menyikat gigi dan mulut kepada sasaran kembali. Penerapan media penyuluhan menggunakan software audiovisual dapat memberikan perubahan tingkat kebersihan gigi, pengetahuan kesehatan gigi, dan perilaku menyikat gigi pada anak-anak PAUD Mutiara Kecamatan Pedurungan Semarang. Media penyuluhan software tentang kesehatan gigi yang diterapkan di Pos PAUD Mutiara dapat dijadikan suatu program pembelajaran di bidang kesehatan gigi.
\end{abstract}

Kata kunci: Software interaktif media penyuluhan, ; Anak PAUD

Abstract

[INTERACTIVE MEDIA APPLICATION SOFTWARE EDUCATION MEDIA AS CHANGES IN THE LEVEL OF KNOWLEDGE AND BEHAVIOR AND DENTAL HEALTH DENTAL HYGIENE IN CHILDREN OF PEARL PEDURUNGAN ECD SEMARANG] The structure of teeth in childhood, early childhood is the period of milk teeth are susceptible to dental caries. Dental caries is the formation of holes in the tooth surface caused by germs and open gear formed on the surface that is associated dental crown dental health maintenance behaviours are influenced by factors outside the individual and the individual. The purpose of community service has Occurred change the level of knowledge and behaviour about oral health and oral hygiene level of the child - the child early childhood Pearl Pedurungan after being given counselling using an interactive software as a medium of education. Implementation methods devotion this by combining several stages of activities, namely: Taking the initial data by performing a dental hygienist, the level of knowledge of children and toothbrushing behavior to the target, Stage interventions: Counseling Program software, Demonstration brushing, Monitoring during the week and two weeks with the observation of parents at home, data retrieval end of the examination of dental hygiene, knowledge and behavior of children brushing teeth and mouth to the target return. Application of audiovisual media

\begin{tabular}{ll}
\hline *) drg. Ani Subekti, MDSc, SpKGA & using a software extension can provide a \\
E-mail: anipurwanto@gmail.com &
\end{tabular} 
change in the level of dental hygiene, dental health knowledge and toothbrushing behaviour in children early childhood Pedurungan Pearl District of Semarang. Media education on dental health software that is applied in the Post ECD Pearls can be used as a learning program in the field of dental health.

Keywords: Software interactive media outreach ; ECD Children

\section{Pendahuluan}

Anak usia pra sekolah merupakan kelompok umur yang rentan terhadap penyakit gigi dan mulut terutama karies. Dalam meningkatkan kesehatan gigi dan mulut salah satunya perlunya dilakukan pemeliharaan kebersihan gigi dan mulut sejak dini.Pada umumnya anak-anak senang mengkonsumsi jenis makanan yang mengandung gula dan jarang membersihkannya.Pemeliharaan kebersihan gigi dan mulut anak melibatkan interaksi antara anak, orang tua dan petugas kesehatan gigi.Pengetahuan, sikap dan praktik/perilaku orang tua terhadap kesehatan gigi dan mulut menentukan status kesehatan gigi anak kelak. Orang tua harus mengetahui cara merawat gigi anaknya, dan orang tua juga harus mengajari anaknya merawat gigi yang baik. Akan tetapi, banyak orang tua yang beranggapan bahwa masa gigi pada anak - anak tidak penting

Pemulihan kesehatan gigi dimulai ditunjang oleh keberhasilan program mengenai kebersihan gigi dan mulut dapat dilihat dengan indikator OHIS (Oral Hygiene Index Simplified). Pengetahuan atau kognitif merupakan aspek pembelajaran yang sangat penting untuk terbentuknya tindakan seseorang (overbehavior). Dalam proses pembelajar praktik dikenal berbagai metode diantaranya demontrasi. Pelaksanaannya bisa menggunakan benda sebenarnya dan bisa menggunakan benda tiruan.Penyuluhan bagi seorang anak haruslah menarik maka salah satu media penyuluhan untuk mengatasi menurunnya minat seseorang pada suatu materi adalah dengan media penyuluhan modern dalam dunia pendidikan adalah komputer.Komputer digunakan sebagai salah satu pilihan penggunaan media pendidikan yang sifatnya dapat men gakses berbagai macam data.Revolusi teknologi komputer yang semakin canggih dengan ukuran semakin kecil namun memiliki kapasitas dan kecepatan yang semakin besar,fungsinya semakin meluas seiring dengan berkembangnya temuan-temuan kreatif perangkat lunaknya (software) akan menyebabkan terjadinya revolusi dalam belajar (Gordon Dryden \& Jeannatte Vos, 2003)

Masalah kesehatan gigi dan mulut merupakan masalah yang rentan dihadapi oleh kelompok anak usia dini (PAUD). Struktur gigi pada masa anak-anak usia dini adalah periode gigi susu yang rentan mengalami karies gigi. Karies gigi ialah pembentukan lubang permukaan gigi disebabkan kuman dan terbentuk pada permukaan gigi terbuka yaitu mahkota gigi terkait perilaku pemeliharaan kesehatan gigi yang dipengaruhi faktor individu dan di luar individu.

Berdasarkan penelitian yang dilakukan di Jakarta menunjukkan $85 \%$ anak prasekolah seudah mengalami karies gigi (Darmawan, Nirham, \& Nursalim, 2014). Sebagaimana kita ketahui bahwa kesehatan gigi merupakan bagian intergral dari kesehatan secara keseluruhan yang dapat mempengaruhi kualitas hidup. Prevalensi karies gigi dan penyakit periodontal tinggi di masyarakat dan hasil penelitian menunjukkan karies gigi mempunyai dampak yang luas, yaitu gangguan pada kualitas hidup antara lain keterbatasan fungsi, disabilitas fisik, ketidak nyamanan psikis dan disabilty psikis.

Perilaku anak Indonesia di dalam menjaga kesehatan rongga mulut masih rendah. Perilaku tersebut timbul karena kurangnya pengetahuan anak mengenai pentingnya pemeliharaan gigi dan mulut, sehingga mereka mengabaikan kebersihan gigi dan mulut (Darwita, 2011). Hal ini, menjadi penyebab timbulnya masalah kesehatan gigi dan mulut yang sering terjadi pada anak usia prasekolah (PAUD).

Pendidikkan Anak Usia Dini (PAUD) Mutiara dengan alamat di Jl. Singa Raya Kelurahan Kalicari Kecamatan Pedurungan Kota Semarang didirikan atas Keputusan Kepala Dinas Pendidikan Kota Semarang Nomor tanggal 7 Desember 2009 dengan nama PAUD Mutiara. Pada saat ini dikelola oleh 5 guru PAUD. Banyaknya murid berjumlah 50 anak.

Berdasarkan uraian di atas, maka sebagai wujud rasa tanggung jawab terhadap peningkatan derajat kesehatan masyarakat dan sebagai bentuk pengamalan Tri Dharma Perguruan Tinggi, Jurusan Keperawatan Gigi Poltekkes Kemenkes Semarang bermaksud untuk melakukan pengabdian kepada masyarakat dengan metode kombinasi antara demontrasi dan dengan software yang hasil akhirnya adanya peningkatan pengetahuan 
tentang kesehatan gigi dan mulut. Berdasarkan hasil penelitian Subekti dkk. (2015) software media interaktif tentang penyuluhan kesehatan gigi anak dapat memberikan perubahan tingkat pengetahuan kesehatan gigi menjadi lebih baik.

\section{Metode}

Metode pelaksanaan pengabdian ini dengan memadukan beberapa tahap kegiatan yaitu: Pengambilan data awal dengan melakukan pemeriksaan kebersihan gigi, tingkat pengetahuan anak dan perilaku menyikat gigi kepada sasaran, Tahap intervensi : Penyuluhan Program software, Demonstrasi menyikat gigi, Monitoring selama seminggu dan dua minggu dengan pantauan orangtua di rumah, Pengambilan data akhir dengan melakukan pemeriksaan kebersihan gigi, tingkat pengetahuan anak dan perilaku menyikat gigi dan mulut kepada sasaran kembali.

\section{Hasil dan Pembahasan}

Pelaksanaan pengabdian masyarakat pada tanggal 7 Agustus 2017 di Pos PAUD Mutiara Kelurahan Kalicari Pedurungan Semarang. Adapun acara pertama yaitu Pembukaan pelaksanaan kegiatan yang dihadiri oleh Tim Pengabdi, mahasiswa, anak-anak PAUD, orang tua anak, Guru dan kepala sekolah PAUD Mutiara.

Jumlah anak PAUD Mutiara yang mengikuti acara pengabmas dari awal sampai akhir sebanyak 40 anak. Pengabdian Masyarakat ini merupakan kelanjutan dari pengabdian masyarakat yang sudah dilaksanakan pada semester Genap TA 2016/2017. Bentuk pengabmas berupa penerapan Media penyuluhan menggunakan software interaktif dan dibantu dengan kegiatan demonstrasi

menyikat gigi. Data hasil pengabmas berupa perubahan tingkat kebersihan gigi, perilaku menyikat gigi dan tingkat pengetahuan kesehatan gigi. Guru PAUD mengawasi evaluasi cek list cara menyikat gigi anak di rumah pada minggu I dan minggu II. Adapun hasil kegiatan pengabmas adalah sebagai berikut:

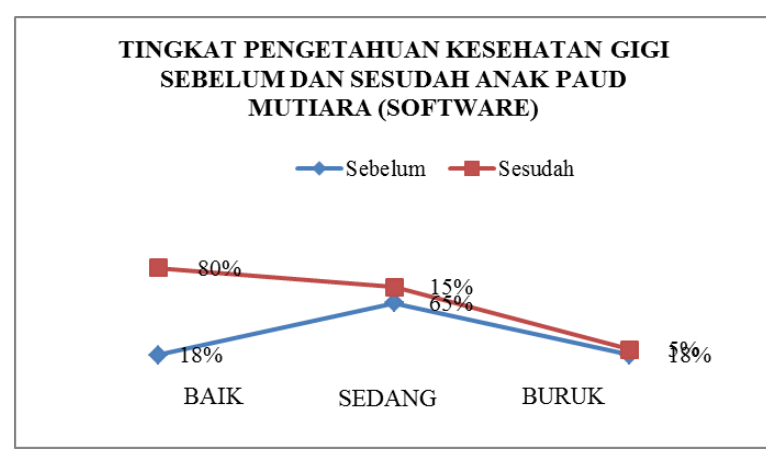

Gambar 1 Grafik Distribusi Frekuensi Tingkat Pengetahuan Kesehatan gigi pada anak PAUD Mutiara

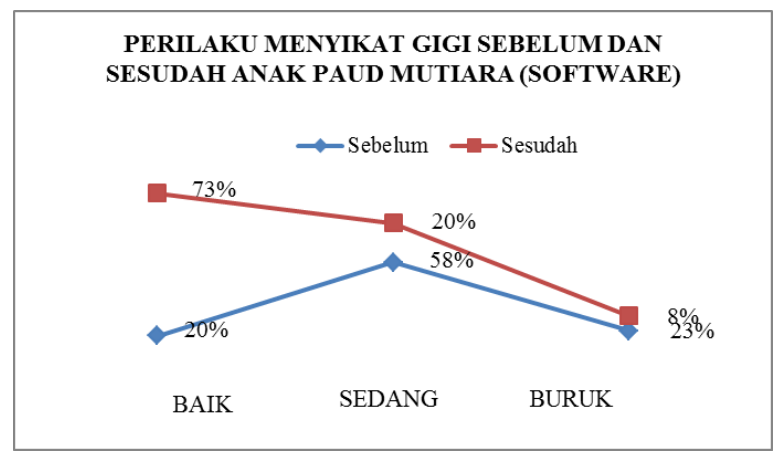

Gambar 2 Grafik Distribusi Frekuensi Perilaku Menyikat gigipadaanak PAUD Mutiara

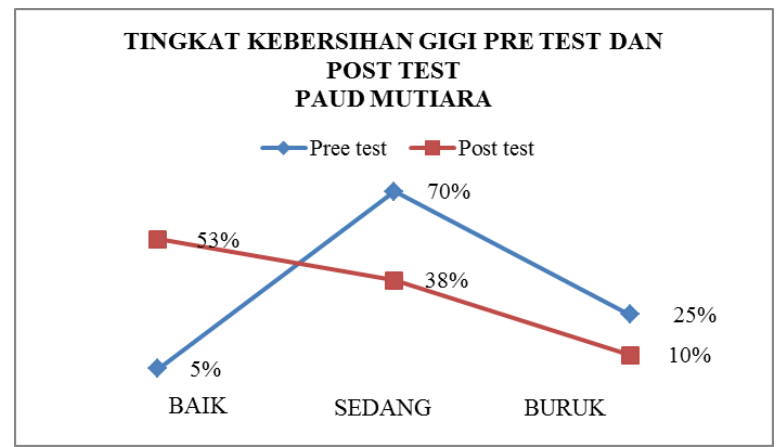

Gambar 3 Gambar 3 Grafik Distribusi Frekuensi Tingkat Kebersihan gigi pada anak PAUD Mutia

Tabel 1. Data hasil cek lis kegiatan menyikat gigi anak PAUD Mutiara pada hari ke-0 (pretes), hari ke-7, hari ke -14

\begin{tabular}{clccc}
\hline No & Hal cara menyikat gigi & Hari ke-0 & Hari ke-7 & Hari ke-14 \\
\hline 1 & Menyikat Gigi Sendiri & $70 \%$ & $78 \%$ & $85 \%$ \\
2 & Gerakan Bulat-bulat/Putar-putar & $78 \%$ & $81 \%$ & $96 \%$ \\
3 & Permukaanyang disikat & $85 \%$ & $93 \%$ & $96 \%$ \\
\hline
\end{tabular}


PAUD menggunakan prinsip-prinsip berorientasi pada pertumbuhan dan perkembangan anak, bermain sambil belajar yang didukung lingkungan yang sehat, menarik, menyenangkan dan a man nyaman yang dapat menimbulkan rangsangan pendidikan semua aspek perkembangan (Depdiknas, 2006). Menempatkan anak sebagai subjek pendidikan. Semua kegiatan pembelajaran diarahkan atau berpusat pada anak menggunakan berbagai media edukatif dan berbagai sumber belajar termasuk lingkungan sekitar untuk mengembangkan berbagai kecakapan hidup (life skill), kecakapan sosial (social skill).

Pembelajaran dilakukan secara bertahap, dimulai dari konsep yang sederhana sejak ibu melahirkan dan menyusui, hal-hal yang dekat dengan anak sampai kepada proses pembelajaran aktif, kreatif, inovatif, efektif, dan menyenangkan dilakukan melalui kegiatan kegiatan yang menarik dan menyenangkan. Memotivasi untuk berpikir kritis, dan menemukan hal-hal baru.

Penerapan media software dapat memberikan informasi kesehatan gigi pada anak PAUD dan memberikan pengaruh perubahan tingkat pengetahuan kesehatan gigi dan perilaku dalam menyikat gigi menjadi baik. Edukasi dengan media software audiovisual dapat memberikan pengaruh terhadap perubahan kebersihan gigi. Hal ini dapat disebabkan berbagai macam penyebab, media software dalam menyampaikan informasi tentang menjaga kebersihan gigi dan mulut sangat menarik, sikap anak dalam pelihara diri sendiri mendapat bantuan orang lain dan peran orang tua dalam pemeliharaan kebersihan gigi anak dengan usia 4-5 tahun masih besar. Hal ini sesuai dengan pendapat Carol \& Barbour (1990) orang tua memiliki tanggung jawab untuk menransformasi nilai dan norma. Orang tua harus memiliki pengetahuan dan keterampilan agar mampu melakukan pendidikan kepada anaknya, memelihara dan mengasihi (Joan, 1995).

Hasil ceklist kegiatan menyikat gigi mengalami perubahan yaitu dari semula banyak yang menyikat gigi dibantu orang tuanya pada saat evaluasi monitoring hari ke-7 dan hari ke-14, anak anak sudah melakukan penyikatan gigi sendiri tanpa di bantu orang tua. Hal ini orang tua mempunyai keinginan bahwa anaknya harus mempunyai ketrampilan menyikat gigi dengan baik. Demikian juga anak-anak akan berusaha untuk menyikat giginya sendiri tanpa bantuan orang lain.
Menurut Notoatmodjo (2012) anak juga belajar dari apa yang mereka lihat, dengar, dan dari pengalaman tentang suatu kejadian. Anak belajar melalui pengamatan mereka terhadap suatu kegiatan yang dilakukan ibu-ayah atau gurunya. Anak belajar dari apa yang mereka dengar dari orang tua dan orang orang sekitar mereka serta lingkungannya. Anak akan meniru kegiatan ibu-ayah sehingga mereka memperoleh pengalaman tentang suatu kejadian.

Cara menyikat gigi juga mengalami perubahan yang semula yang disikat bagian depan saja berubah menjadi semua permukaan gigi. Dan gerakan menyikat gigi yang semula maju mundur berubah menjadi gerakan berputar-putar. Materi penyuluhan tentang cara menyikat gigi dan di demonstrasikan oleh para pengabdi kepada anak-anak PAUD dan orang tua membuat anak-anak PAUD mengalami perubahan perilaku cara men yikat gi ginya. Pada anak usia prasekolah (PAUD) sebagian besar menghabiskan waktu mereka dengan orang tua atau pengasuh mereka, khususnya ibu. Hal inilah yang menunjukkan bahwa pemeliharaan kesehatan gigi mulut anak dan hasilnya dipengaruhi oleh pengetahuan ibu dan apa yang dipercayainya.

\section{Simpulan dan Saran}

1. Penerapan media penyuluhan menggunakan software audiovisual dapat memberikan perubahan tingkat kebersihan gigi, pengetahuan kesehatan gigi, dan perilaku menyikat gigi pada anak-anak PAUD Mutiara Kecamatan Pedurungan Semarang

2. Kegiatan menyikat gigi anak mengalami kemajuan prestasi yaitu pada anak PAUD Mutiara melakukan sendiri tanpa bantuan orang lain

3. Gerakan menyikat gigi mengalami perubahan yang tadinya maju mundur menjadi gerakan berputar putar

4. Gerakan menyikat yaitu yang semula hanya permukaan depan yang disikat berubah menjadi keseluruhan bagian gigi.

\section{Ucapan Terima Kasih}

Terima kasih kepada Direktur Poltekkes Kemenkes Semarang, DIPA Poltekkes Kemenkes Semarang yang telah mendanai pengabmas ini, Tim penyusun pengabmas dan semua pihak yang terlibat dalam pengabmas ini. 


\section{Daftar Pustaka}

Darmawan, S., Nirham, A., \& Nursalim. (2014). Faktor-faktor yang Mempengaruhi Kejadian Karies Gigi pada Siswa Kelas 1 di SD Negeri 1 Pekkae Keca matan Tanete Rilau Kabupaten Barru. Jurnal Ilmiah Kesehatan Diagnosis.

Darwita, R. R., Novrida H, Budiharto, Pratiwi PD,Amalia R, Asri SR, 2011, Improving oral health awareness in primary school student, J Indon Med Assoc, Volum: 61, Nomor: 5, Mei 2011.

De Porter Bobbi \& Hernachi Mike, 2002, Quantum Learning (membiasakan belajar nyaman dan menyenangkan), Bandung. Kaifa

Departemen Pendidikan Nasional. 2006. Pedoman Penerapan Pendekatan Beyond Centers and Ccircle time. Jakarta: Diknas

Dryden, Gordon, Jennette Vos ,2003. Revolusi cara belajar (the learning revulation) belajar akan efektif jika dalam keadaan ' fan’ . Bandung: Kaifa

Hariyanti, N, dkk. 2008. Mengatasi Kegagalan Penyuluhan Kesehatan Gigi pada Anak dengan Pendekatan Psikologi.Dentika Dental Journal.Vol 13. No 1.

Joan, F.,1995. How to Raise a Bright Child. London: Vermillion Laelia DA, Mutiara TCS. Indeks karies dan kondisi jaringan periodontal anak SD usia 6-12
tahun,.Prosiding PIN IDGAI V. Makassar;2011

Machfoedz, I. 2007. Metodologi Penelitian Bidang Kesehatan, Keperawatan, dan Kebidanan. Yogyakarta : Fitramaya.

Notoatmodjo, 2012, Promosi Kesehatan Dan Perilaku Kesehatan, PT Rineka Cipta, Jakarta.

Shapiro Lawrence E, 2001, mengajarkan emosional intelligence pada anak, Jakarta. Gramedia Pustaka Utama

Sariningsih, E. , 2012. Merawat Gigi Anak Sejak Usia Dini. Jakarta : Elex Media Komputindo.

Subekti, A, Subinarto, Sutomo, dan Ekoningtyas. A.E , 2015, Application of Software Interactive Education Media in Improving Dental Health Knowledge of Children, International Seminar On Public Health And Education, Proceedings, Public Health Departement Postgraduate Program Semarang State University.597-604.

Wong, D. L. , 2009, Buku Ajar Keperawatan Pediatric. Alih bahasa Sutarno A, Juniarti, N. Vol 1, Edisi 6. Jakarta : EGC. 